\title{
Effect of Augmented Reality and Simulation on the Achievement of Mathematics and Visual Thinking Among Students
}

\author{
https://doi.org/10.3991/ijet.v14i18.10748 \\ Osamah (Mohammad Ameen) Aldalalah ${ }^{(凶)}$ \\ Taibah University, Madina, KSA \\ odalalah@taibahu.edu.sa \\ Zyad Waleed Mohamed Ababneh \\ Ministry of Education, Dubai, UAE \\ Ali Khaled Bawaneh \\ Imam Abdulrahman Bin Faisal University, Dammam, KSA \\ Wafa Mohammad Mahmoud Alzubi \\ Ministry of Education, Abu Dhabi, UAE
}

\begin{abstract}
The purpose of this study was to investigate the effect of augmented reality and simulation on the achievement of mathematics and visual thinking among students. The study sample consisted of 86 students of mathematics divided into two treatments in a random way. This study utilized the quasi experimental type methodology. The independent variables were the instruction (augmented reality \& simulation). The dependent variables were the students' achievement and visual thinking. The findings of this study showed that students using the augmented reality mode performed significantly better than those in the simulation mode in achievements and visual thinking.
\end{abstract}

Keywords - Augmented Reality, Simulation, Mathematics, Achievement, Visual Thinking.

\section{Introduction}

The fear of mathematics learning is now more widely distributed among learners than early years, and there is a large proportion of learners do not like mathematics, are not eager to study it and even hate it. This can be observed through feelings of these learners when they face an arithmetical problem, or a simple math question (Abu Odeh, 2018). Many studies and researches have talked about the difficulty of mathematics, and learners' anxiety and fear of studying it (Cho \& Tee, 2018; Venkatesan \& Karimi, 2009). The hardness of mathematics makes it more complicated, so students alienate from it. In addition, it needs greater effort from teachers in preparation and explanation, which decreases a level of thinking achievement among stu- 
dents. This case is considered a challenge for teachers and parents alike (Ahmed, \& Alastel, 2015). As a result, teaching of thinking skills has become more necessary than ever, the review of educational literature indicates that there are many international attempts to teach thinking and creativity (AL-Musawi, Nasaeif \& Al-Khafaji, 2016).

Everyone agrees that education for thinking or learning its skills is an important goal of education, so schools must do whatever they can to provide thinking opportunities for their students (Samo \& Kartasasmita, 2017). Many teachers and educators consider that the task of developing the student's thinking ability is an educational goal that they place at the top of their priorities. However, this goal often clashes with reality when applied, because the existing educational system does not provide sufficient expertise in thinking. Although the majority of educational staff are convinced of the importance of developing students' thinking skills, and they emphasize that the school's mission is not filling students' minds with information, as much as it is a stimulation of thinking and creativity. Despite of that, these educators live with the practices in our schools, without trying to break the familiar wall or breaking it up (Ersoy \& Guner 2015).

Educators emphasize that the definite interaction between mathematics and technological progress necessitates the educational institutions to develop plans and strategies to facilitate teaching it, and to overcome learning problems as it is an abstract science that is difficult to absorb. Modern technological means contribute in improving and developing the educational process, since they play an essential role in motivating students to learn, and limits the problem of individual differences among learners, they also have become part of the various activities in education, because of their positive effects in providing individuals with knowledge, as increasing motivation and developing mental skills (Farrajallah, 2016). Engineering is one of knowledge branches occupies a distinct position between different sciences and mathematics specifically. Therefore, it requires using different teaching methods in order to raise the levels of higher thinking (Tafesh, 2011).

Two of the revolutionary innovations that have emerged in the last few years are the technology of virtual reality and augmented reality, which are two ways of presenting a substance, so that this content can be seen and possibly interacted in completely different ways. While virtual reality requires full immersion in the digital world, the enhanced one contributes in adding to our view of ((the real world)). In both cases, we are watching some exciting experiences which have been considered a fantasy for a while (Ahmad, 2016).

\section{$2 \quad$ Augmented Reality}

Our contemporary world is living in an epistemological and technological revolution that is growing quantitatively and qualitatively in all life fields in which the education area is the basis of these areas; it supports the other fields and at the same time it benefits from developing these areas. Furthermore, we know that the information technology and the means of communication and technology of education in our lives 
has become an integral part of that revolution (Aldalalah, 2018). So the computer has had a significant role in increasing the speed of moving the wheel of life significantly, Educational institutions should take benefits from computer data in order to keep abreast of the rapid development around them (Shatat, Aldalalah \&. Ababneh, 2017). Educational institutions should take advantage of the development of educational technologies in the educational process, which increases the efficiency of learners and teachers' grant, while educational technology provided, by computers, educational institutions with what is known" augmented reality". This development in the educational technology leads us to benefit and change in the educational process from its traditional position of being a teacher is a prompter, and a student is negative since $\mathrm{s} /$ he only records and preserves the educational material, so the teacher should develop teaching methods and benefit from the technology of education (Abdul Karim, 2010).Our educational reality is known now as "electronic education" since it as an essential role in the educational institutions which are racing to develop their educational systems in order to enhance education quality, to attract more students, especially when the technology of education has contributed to change the way of learners' thinking, and prepare our children for the revolving rapid future (Ibrahim, 2012; Amasha, 2011; Mazen, 2009).

The augmented reality is one of the important concepts that education technology has provided us of, which is meant an integration of the real environment we live into with the virtual reality to provide a reality to offer a new reality grants more than the real reality and virtual reality give, (Nofal, 2010). The new reality is seen as a kind of virtual reality that depends on presenting the real environment with some additional virtual information on the real environment (factual reality) which was not actually part of it, through the computer. Those additions maybe images, sounds or videos help the learner to understand the educational material "the content" more easily and clearly (Khamis, 2015).

The technology of augmented reality is one of the modern methods in the educational process, which is based on the electronic environment, that enriches and supports self-learning and lifelong learning; so that the learner is able to cope with the continuous development and the cognitive knowledge explosion, besides taking into account the principle of the educational individualization in learning, because each student learns according to his capability, and the teacher is a guide and not a prompter (Sirakaya \& Kiliç, 2018 ; AlShami \& Alkade, 2017).

The technology of augmented reality appeared in the early 17 th century, but this technology is modern in its reformulation type agreeing the technological development. The technology of augmented reality is considered a new trend in the education development. The technology of augmented reality can also be used in the educational games for students, since it has possibilities to motivate them to learn by playing, while the technology of augmented reality can present a material for students in a smooth, clear, and motivating curriculum (Alammarji, 2017). This was done by Metaio companyin Germany, where they worked on designing and preparing books based on augmented reality. This technique also wasused by employing it for ARIS program in order to create and produce a virtual gaming environment. 
The augmented reality had limited usage in the early stages of its production in the medical, advertising and industry fields, until it was employed in the education field, where it appeared at the university of Utah and Harvard university when (Ivan Sutherland) invented a helmet with glasses that give a real fact added to 3D images. (Tom caudell) is the first person who called it called the augmented reality technique in 1990, (Khamis, 2015). Figueiredo (2014) defines the technology of augmented reality as the combination and integration of the virtual environment and the real environment into a three-dimensional image to be seen by the learner as a real world. Shea (2014) defines it as a technique, through which there is an interaction with the real learner's reality by combining the real and virtual reality in three-dimensional image, Mushtahaa (2015) defines it as a learning and teaching technology based on threedimensional computational ROM, added to video clips and a camera put for the learner, making him lives in the same information environment. The augmented reality as "a term that explains and describes the technology that blends a realistic synchronized digital content from software and computerized objects with the real world (Sirakaya \& Kiliç, 2018).

The augmented reality as a mean which based on a technology of transferring the factual external environment into digital devices and then processing it digitally by adding some effects to it and then producing it through digital screens. Azuma (1997) suggests that the technique of augmented reality is an "environment combines the elements of the real world with the virtual world elements." He added in (2001) that the augmented reality includes factual reality as well as virtual reality. (Larsen, Bogner, Buchholz, Brosda, 2011) define it as "adding, synthesizing and photographing digital data using digital view ways of the factual reality of the environment which is surrounding the organism. From a technological perspective, the augmented reality is related to computer devices can be worn, or smart devices can be carried.

By looking at the previous definitions of augmented reality, we find that it is a method of teaching based on the addition of a group of information to factual reality, which integrates the factual reality with virtual one, so effects, parameters, videos, photos, data, etc. are put on the real environment of the learner, which increases the information provided for him, while it can be assisted by glasses or helmet contains a camera or through a three-dimensional display. The difference between virtual reality and augmented reality: Virtual reality makes you feel that you are mentally available in a certain place, as if you are part of it, but you are actually not there, but in fact enhanced some of the effects. On the other hand, symbols, effects, and information in the augmented reality are added to the surrounding reality of the learner (environment). Thus, this environment can be seen from various angles and different looks from factual reality, which sustains the learner's sense of the real world by adding some additions that are compatible with reality. However, virtual reality is based on the simulation of real scenes or imaginary scenes. But augmented reality combines between the truth and the virtual world, so here the system controls the optical senses but in the enhanced fact the learner feels himself in the real world, 3D mouse joystick, touch gloves may be used for handling and input in the virtual reality, and in the output, 3D screens, head helmet, vertical monitor, and cave. But in the factual reality, 
smart phones, tablets and laptops are used (Nayyar, Mahapatra, Le \& Suseendran, 2018; Husseini, 2014)

Anderson \& Liarokapis (2014), Ahmad (2018) and Mushtahaa (2015) show the most important features and advantages of augmented reality technique as it enables the teacher and the learner to interact easily with it, and enables the learner to enter his information and data readily, and is characterized of simplicity and high efficiency, moreover, its cost is acceptable while it can be used with more than one student and for multiple generations. Furthermore, it increases the transparency and clarity between the teacher and the learner, so it serves the educational process. It is considered a combination between reality and imagination in a real environment, which is considered to be an interactive nature in the actual time when used, it is threedimensional, illustrating the shapes by 3 dimensions, that makes it easier for the learner to receive and analyze information from different aspects. In addition, it do not need a special learning environment that can be applied in a classroom, increasing the activity and interaction of the classroom, it also combinates the actual teacher's explanation with the added digital environment, which increasing students motivation and fascination and using the senses more effectively. It promotes communication and social interaction among students in the educational environment., which provides explanations about the risk situation without the need of the direct student's presence, besides facilitating the handling of hazardous materials, taking into account individual differences, especially through the control of display time. It also offers a possibility of downloading the program on the phone, in order to ease a group learning and dialogue in problems solving. The augmented reality strengthens the factual natural reality by adding videos, images, and $3 \mathrm{~d}$ models to the natural reality.

Sidiq, Lanker \& Makhdoomi (2017), Kulkarni, Takawale (2016), Al-Khalifa \& AlOtaibi, (2015) and Husseini (2014) presented a range of suggestions to benefit from the technology of augmented reality efficiently in the education and overcoming the difficulties that encounter the technical operators: the augmented reality offers the possibility of providing exploration-based learning in all subjects, particularly, science and history, the possibility of employing the textbook and making it more vibrant instead of its inertia, through the videos, images, sound and three-dimensional images (interactive book) which based on the augmented reality. Besides teacher training and joining him into courses that develop his/ her of ability in the augmented reality technique, as providing an educational content that takes into account individual differences among learners. Providing an effective experience for students who have special needs, so that the technique is suitable for them in their classes, also, working to support and disseminate education technologies between families, teachers and learners, and benefit from others experiences in developed countries in the field of technology of augmented reality, besides watching and using other studies in the education field.

The study of Husseini (2014), which aimed to learn the impact using the augmented reality technique in the result of the computer course at the cognitive levels (remembering, understanding, analysis) among the students of the secondary third grade in the city of Makkah and trends towards it. The sample of the study consisted of (55) female secondary third-grade students, 28 students of the experimental group studied 
using the augmented reality technique, and 27 students of the controller group was studied using the traditional method of computer teaching. Results showed the existence of statistically significant differences between the modified averages of the experimental and the controller groups in a dimensional results at the level (remembrance, comprehension, analysis, total) of female students after adjusting the preceded result, and there are statistically significant differences between the averages measurements, the preceded and the following of the experimental students group in the measure of the technical trend. In the study of Alamraji (2017), which was aimed at knowing the effectiveness of using the augmented reality technique in teaching history for the first secondary grade on the development of results, the skills of historical thinking, and the motivation to learn by using the techniques of students, the results of the study indicated the success of the augmented reality technique in developing results, the skills of historical thinking, and motivation to learn by using the techniques for students.

In the study that was conducted by Aqel and Azzam (2018), that aimed at knowing the effectiveness of using the augmented reality technique in the developing the achievement of seventh grade students in chemistry in the Gaza Strip by using the program ( $4 d$ Elements), the sample of the study was made up of (93) seventh grade students, the results showed statistically significant differences between the average grades of the controller and experimental groups in the dimensional test in favor of the experimental group. As that the augmented reality technique achieves a high efficiency of more than (1.2) according to the modified earning of the Black in raising the level of students in the subjects of chemistry.

The Beers perez - lopez \& Contero (2013) aimed to determine the extent to which the augmented reality technique can be used to deliver multimedia content to support the teaching process of the digestive and circulatory systems at the primary school level in Spain, and its impact on retaining with knowledge. The study sample was made up of (19) female students and (20) male students in the fourth grade. The results of the study showed that students who studied through the technique of augmented reality, their memorizing of knowledge was bigger, while the students who studied through the traditional method had lower was less.

The results in the study of Sumadio \& Rambli (2010) indicated that the augmented reality technique helps students save and keep information for longer time and easier, because the technique based on (code system) such as videos and 3D virtual objects that enable them to integrate with it in the learning process. The technology of augmented reality can be employed in the educational learning process to serve learners in their dealings with educational materials and information, so that they may visually manage them better than the fact and the virtual reality (Catenazz \& Sommaruga, 2013).

The augmented reality technique from Chiang, Yang \& Hwang (2014) point of view has a significant impact on increasing the learner's motivation towards learning to achieve the desired goals, Moreover, Al-Mutairi (2016) asserts that the augmented reality technique is a revolution in the field of education, due to its advantages such as providing self-learning and long-lasting learning to the learner, as keeping up with technology and increasing the learner's motivation by managing his experience and 
suspense. Furthermore, it has the obvious effect in simplifying subjects and topics that are difficult to reach in reality or cannot be clarified as in the case of material, atoms and chemical compositions.

\section{The Simulation}

Technologies have become an indispensable necessity in everyday life, because of the facilities they offer to human society in all its fields, due to the tremendous, rapid and successive progress of the technological development, and which accompanying it of increase and flow in knowledge, information and discoveries in a way that is hard to predict. This development reflected on the field of education and its educational and psychological theories of what is best for learners. So, states are competing in their using of educational technology, computer and various software in the educational process (Aldalalah, 2018). Thus, it has become necessary for countries to work on restructuring and regulating knowledge, and to model educational experiences , The role of computers in the educational process has been varied, as it is distinguished from other educational means; the computer is not a goal in itself, but its diverse programs, make its role is changing distinctively( Alsultanny, Nouby and Enazi, 2014 ). Therefore, the computer came to solve and dispel the obstacles faced by the controllers of the educational process, so that the educational institutions are considered the gateway through which we produce generations able to face the future with all the rapid developments and innovations, by finding the capable learner with life-long learning, keep up with evolution (Abu Madi, 2011).

The simulation method is a software program based on the innate basis of learners, because it is based on suspense and pleasure in addition to self-expression, besides reflecting the learner's mental and psychic abilities, and emptying the learner's psychological stress (Liu, Chia \& Huang, 2011). Using the simulation program is due to its significant impact on the development of higher thinking skills such as the ability to analyze, install, apply and innovate, and to save time, effort and money, because of the seriousness of some educational attitudes as a chemical experiments, and may be due to the difficulty of applying this situation practically like volcanoes and nuclear reactors. It also provides learners with a lot of activities that are difficult to apply in school science labs (Almousa \& Abed, 2016). The advantages of the educational simulation are as described by Gagne (1987) who is pointed as (Abdulaziz, 2013).

It shows a daily practical life situation, and provides the learner with the possibility of training, control of the educational condition according to the learner's ability, furthermore, it enables the learner to ignores some useless and unimportant situations, and enables him/her to be more active and effective in the learning process. Simulation is a tool used to produce interactive material for specific or non-specific interactive activity in order to list or review a particular function. (Koparan \& Y1lmaz, 2015).

Almousa \& Al-Abed (2016) defines it as the "process of representing or creating a set of situations representing or imitating real-life events, in order to be presented and deepened easily to discover their secrets, and to identify their possible results closely." From the point of view of Sophie (2010), simulation is a set of educational situations 
that includes a system that actually exists in reality, and is represented through computer in the form of equations that provide high accuracy of the interrelationships between its different components. The learner in the simulation faces similar attitudes in his daily life, when the computer plays the role of the teacher and the learner through the programs it offers, resulting a fruitful interaction with the learners (Rutten, Wouter \&, Jan, 2012).

Al-Hamdani (2002) defines it as an abstract or illustrative simplification of a real situation, or a process, in which participants play active roles. Maqat (2016) sees it as a predictive rather than a standard technique, the purpose of which is to guess what the results of predictive measurements will be, and based on a conceptual vision or model of a real system even if this model does not already exist. When the simulator system exists, predictive measurements depend on the efficiency of the simulator system and not on the real system itself, that is, the simulation is the use of numerical logical models of a system, concept, or process to detect the expected behavior in it over time. (Al-Sarayra, Al-Rifa \& Jouifel, 2017).

Computer simulations from Brunner's point of view, who is pointed in Masoudi \& Al Mazrou (2014) are considered to be an effective method in the educational process, while learning is done in the learning environment through discovery, so the learner easily moves from one point of another through observations, examples, attempt, error and binding between reasons and results he sees to reach to conclusions of the outcome. The simulation is a model or example of a real situation and it is assigned to all those who contribute to it a specific role in which s/he encounters certain difficult circumstances and must provide the solutions for encountered problems in these circumstances to make appropriate decisions (Ruwaili, 2011). The simulation in the glossary of educational terminology was defined as an educational technique that simulated a real-life attitude, where students and teachers performed teaching situations as an attempt to make the theory practically and realistically oriented (Eubayd, 2014).

The study of Al-Hiyawi \& Saleh (2011) aimed at detecting the impact using simulation modelling of astronomy in the achievement of second-grade students, physics department and develop their attitudes towards learning. The sample of the study consists of (61) male and female students of the second graders, department of physics in the Faculty of Education for the Year (2009-2010). These students were distributed for two groups: the experimental and in the modeling program, and the controller in the usual way. The results showed a statistically significant difference between the average of results between the two groups in the subject of astronomy, in favor of the experimental group.

The study of Masoudi \& Al Mazrou (2014), which aimed at studying the effectiveness of computer simulation according to the survey of developing the conceptual absorption in physics among high school students. The sample of study was made up of (63) students in the scientific secondary second grade, by using the semiexperimental design. The results of the study showed a statistically significant difference between the grades average of the experimental group students who studied the continuous power circuits using the simulation method according to the survey, and the grades average of female controller's group students who studied using the survey 
method in the comprehension test, and in the six aspects of comprehension, and in favor of the experimental group.

The study of Shaltout \& Fayez (2017) aimed to learn the impact of using interactive simulation in the development of the results of students in the sixth grade in the subject of science. This study applied to the students of the sixth grade, 20 students in the experimental group and 20 in the controller group. The researchers followed the semi-experimental method. The results of the study showed statistically significant differences between the grades average between the experimental and the controller groups at the level of remembering, comprehension, application, analysis, and synthesis, in favor of the experimental group. The study of Abdulaziz (2013) aimed to measure the impact of an e-learning environment designed on a simulate computing for developing some librarian working skills, especially the skills of operating and maintaining modern office devices, and to improve the degree of learning depth among students of commercial secondary schools. The sample of the study was made up of (62) male and female students of the third year in commercial secondary schools. The researcher used the semi-experimental method in the applying the study. The results of the study showed statistically significant differences between two groups, as acquiring the skills of operating, using, and maintaining librarian devices for the experimental group, as well as a noticeable improvement in the level of learning depth of the experimental group.

\section{$4 \quad$ Visual Thinking}

Human life cannot be imagined without thinking, and thinking is seen as a forward of intelligence in the human being to achieve his goals and solve his problems, etc. So thinking is a skill that individual trains on every day and s/he is learning. Abu Dan (2013) defines thinking as "an organized mental process that an individual is doing when confronted with a problem, so he organizes his previous ideas and information to in order to reach a solution to the problem in a scientifically method and purposeful way. Tafesh (2011) define it as "A system of processes that the mind employs to organize its experiences in a new way to solve a specific problem, so that this system includes the processes of understanding the relationship between the introductions and results, and the processes of understanding the relationship between cause and effect, between the public and the private, and between the known And the unknown. This system is purposeful and targeted to achieve an intentional goal that may be an idea, or to judge a phenomenon, solve a problem, or make a decision. " There are three ways of thinking that are categorized according to human senses: auditory thinking, visual thinking, and emotional thinking (Osaimi, 2015).

Educators and scientists in the educational learning process believe that the use of visual input is an urgent necessity, as it works to understand the teaching material more quickly and clearly, because the drawings, images and forms that are available in the educational curriculum increase the comprehension of learners (Farrajallah, 2016). Visual thinking is considered a type of thinking that works to stimulate mental abilities using visual stunts, it is the individual's ability to recognize the similarities 
and differences between visual objects and convert them into literal language, that may be spoken or written in order to gain access to new knowledge and information based on former experiences. Visual thinking is the process of insight into mental images, when mental images are mental drawings of the individual's sensed experiences in addition to imagination, so the visual thinking shows us how to deal with the elements of the surrounding environment, which is symbols, through the mental images (Tarigan \&Yusnadi, 2017).

Salem \& Abud (2017) define it as it is perception and discrimination, the visual interpretation of things, shapes and objects, and the organization of mental images in various modes through different modes by some processes such as deletion, addition, reflection, rotation, bending and cutting, and then work to find relationships between them and translate them into positions and literal symbols in order to reach conclusions. Alshalawi (2017) believes that visual thinking is a set of successive consequent mental processes that the human brain undergoes when exposed to visual stimulants in order to gain access to verbal meaning, storing it and retrieve when needed. Visual thinking is important in the educational process, while most literal language has been changed to visual one. Salih (2017) state that the visual thinking helps the learner understand, organize and structure information, as develop the ability of innovating and producing new ideas, it also develops the ability to solve problems by developing the ability to understand educational visual messages. Furthermore, it works to attract the attention of the learner towards the subjects of the study, which helps to understand abstract concepts in an easy and interesting way, and that links and organizes ideas and information in images and forms easy to understand.

Visual thinking also helps to access non-visible information through shapes and objects. Educators have been interested in visual thinking skills. Surya, Sabandar, Kusumah \& Darhim (2013), defines visual thinking skills as a "system of processes consisting of a set of skills that encourage the learner to think visually, meditate and translate these images into written or spoken languages and conclude information. From visual thinking skills levels of visual image reading: (Figure recognition) is the ability to recognize what the image, shape, or graphic contains, its number, its names and dimensions, (Description) means the individual's ability to describe the molecules and the main and sub-details in the image and shape accurately, (Analysis) It means the ability to categorize the elements of the visual stimulant and work to assemble them in order to locate them on the learner's information network, bring and link them to previous experiences (Tafesh, 2011). (linkage and installation) means the ability to link elements and parts of a picture or shape as well as to link them to previous information and experiences, besides developing the concept and hypotheses of the senses that have been concluded through the linkage and construction of these elements and place them in a single integrated template (interpretation and conclusion of meaning) means the capacity of learner to reach the concept, meaning and significance emanating from the image or the dramatic form in order to get the outputs from the process of visual thinking.(Criticism and creativity) note the strong and weak aspects of the stimulus image, and using and recruiting the information in new positions (Tafesh, 2011). 


\section{$5 \quad$ Problem of the Study}

The development of student thinking skills is very important to them as they are able to acquire creative abilities. This, in turn, is also reflected in their colleagues and teachers. Furthermore, these methods are considered methods of developing students ' skills and increasing their awareness of the importance of these skills to develop their thinking processes and strategies of the important topics that deserve research and attention.

The problem of the current study is that there is a weakness in the teaching methods, which is in the thinking development in general and higher cognitive processes especially, and achievement in mathematics in the seventh grade students in the geometric shapes unit. From here researchers recognize that the interest in developing achievement and thinking of students became a necessity, and because the subject of visual thinking skills has not been studied by researchers, especially to school students in the United Arab Emirates, so researchers have a desire to work to develop the skills of visual thinking and achievement of students.

Despite continuing efforts to develop education, the level of students in mathematics has not risen to a satisfactory level, perhaps because efforts have not focused sufficiently on using modern teaching methods. It is noted that during the researcher teaching of students in the current study and because of the necessity and importance of thinking development in general, and visual thinking in the unit of geometric shapes for seventh grade students in mathematics, this study came as a try to find the impact of teaching in two ways of learning through designing module geometry formats using augmented reality mode, comparing with simulation method.

\section{Study Questions}

The present study attempts to answer the following questions:

- Are there statistically significant differences in the achievement of seventh grade students in mathematics attributed to the teaching method (Augmented Reality, Simulation)?

- Are there statistically significant differences in the visual thinking skills of seventh grade students in mathematics attributed to the teaching method (Augmented Reality, Simulation)?

\section{$7 \quad$ Research Hypotheses}

- H1: Students using the Augmented Reality mode will attain significantly higher post test score (PTS) than students using the Simulation mode.

- H2: Students using the Augmented Reality mode will attain significantly higher visual thinking test score than students using the Simulation mode. 


\section{Significance of the Study}

On the other hand, this research study is useful for curriculum designers. It would help them understand the importance and effect of varied implementation of the augmented reality and simulation through instructional programs on mathematics learners. It contributes to developing new mathematics teaching strategies, mathematics skills and learning methods taking into consideration the perceived role of mathematics in our life as well as our education. It would provide them the design and develop an instructional program with two mathematics learning treatments (i.e., software applications) on the primary seventh grade primary students. This is conducted by employing the multimedia in the two instructional programs.

In this regard, the findings and results of this research study will be useful in providing mathematics teachers and teaching materials designers to consider the significance and effect of varied implementation of the augmented reality and simulation through instructional programs and incorporate them in the provided mathematics teaching and learning materials. Furthermore, this study will have great contribution to research on mathematics in a Jordanian context. The Jordanian Ministry of Education along is exerting great efforts to activate the role of mathematics such as employing it in the educational process and using as instructional aide.

Consequently, the current research hopes to shed light on the significance of varied implementation of the augmented reality and simulation through instructional programs and their contribution to the learning of mathematics. This study is important as it goes beyond the traditional approaches by making comparisons within a single method in an attempt to present information in a way leading the learners to handle such mathematics knowledge. In contrast, the traditional methods which have no theoretical basis would yield confusing results and contribute to ineffective learning by Students. Its importance is related to its emphasis on the aptitude-treatment, which concerns with one's improved characteristics acquisition by presenting treatments or applications that meet the abilities and readiness.

\section{$9 \quad$ Methodology}

To answer the study questions, the researchers adopted quantitative approaches. The researchers used quasi-experiment design to identify how effective was augmented reality and simulation and effect of achievement and visual thinking skills in mathematics by the seventh grade students.

\subsection{The study sample}

The study sample consisted of all seventh grade students at Al Manar School in Abu Dhabi and enrolled in the second semester of the academic year (2018-2019). They were selected in the available way. The sample of the study consisted of 86 students of mathematics divided into two treatments in a random way. The first treat- 
ment is taught through the augmented reality and the second treatment is taught through simulations.

\subsection{Study variables}

This study investigated the following variables:

- Independent Variable: teaching method (augmented reality and simulations)

- Dependent Variable: achievement and visual thinking skills.

\subsection{Instrumentation}

The mathematics test: To achieve the objectives of the study, a achieving test was built from a multiple choice test type from the geometric shapes unit of the seventh grade students to be used as a before and after test on the study groups, then identifying teaching objectives for these lessons as contained in the textbook, after reviewing the school curriculum which is the environment of the study and calling a number of educational supervisors as arbitrators. These teaching objectives are distributed to the units of the study. The jury has been asked to classify the teaching objectives at its level of excellence: remembering, understanding, applying, analyzing and composing. The teaching objectives and their relative measures in accordance with knowledgeable levels by units.

The test questions, which numbered 30, were then developed and written through helping of a number of the seventh grade teachers, then presented to the arbitrators for their opinion and observations, and to ensure that the content was validated for testing. After that the test was rearranged and the number of its paragraphs became (20), from the type of multiple choice and accrediting one mark per paragraph of the test in the case of correct answer and zero in the case of incorrect answer or no answer. The test was applied to an experimental sample chosen randomly, to estimate the difficulty and discriminative factors for the test paragraphs. The difficulty of the paragraphs for the test ranged from $(0.33-0.64)$, and the distinguishing coefficients between $(0.36-$ 0.62 ). To confirm the reliability of the test was calculated by applying the equation of the Alpha Cronbbach and the value of 0,82 and internally consistent 0.79

Visual thinking test: This test depends on the visual thinking, which was designed by Mokly (2013), and applied it on the middle stage in Saudi Arabia. It is constituted of 21 paragraphs. It is a one dimension test, and every paragraph is answered by choosing one answer only from four choices and according to the instructions of the test, which show for the examinee how to answer on. Mokly (2013) made sure of his appearing credibility and persistence when the persistence coefficient amounted to 0 , 89. The researchers ascertained the sincerity and persistence of the study community by presenting it to a group of arbitrators and concluding the persistence coefficient of which reached 0.87 and internal consistency amounted to 0.81 . 


\section{Results}

\subsection{The pre quasi - Experimental study results}

The purpose of the pre- quasi experimental study was to test the assumption that the participants across the groups were equivalent in prior knowledge of mathematics for seventh grade primary Students. To test that the participants across the groups were equivalent, the pre-test was conducted three weeks before the beginning of the study. The pre-test papers were scored by the researcher. To determine if there were statistically significant differences between the groups' mean scores, the scores of the groups were entered into the Statistical Package for Social Science (SPSS) for Windows computer software.

\subsection{Group's equivalence}

The purpose of the pre-experimental study was to test the assumption that the participants across the groups were equivalent of mathematics for seventh grade primary students. To achieve this purpose, a pre-test that measures was conducted before the beginning of the study. To examine the equality of treatment mode on pre score, the ttest procedure was used (Table 1)

Table 1. T-test of the Pre-test Scores to Measure the Equality of Groups

\begin{tabular}{|l|l|c|c|c|c|c|c|}
\hline & \multicolumn{1}{|c|}{ Groups } & $\mathbf{N}$ & Mean & Std. Deviation & t & df & Sig. \\
\hline \multirow{2}{*}{ Pre test } & Augmented & 42 & 5.0714 & 1.48805 & \multirow{2}{*}{-.194} & \multirow{2}{*}{84} & \multirow{2}{*}{.847} \\
\cline { 2 - 7 } & Virtual & 44 & 5.1364 & 1.60799 & \\
\hline
\end{tabular}

Table 1 showed that there is no significant difference in the pre test scores in groups. This means that the groups have the same level of prior knowledge of mathematics forseventh grade primary students. And the researchers have also verified data homogeneity and natural distribution

\subsection{Testing hypothesis}

H1:.Students using the Augmented Reality mode will attain significantly higher post test score (PTS) than students using the Simulation mode.

Post Test Score of students in the Groups: The corresponding hypothesis is stated as below:

Students using the (AR) mode will attain significantly higher post test score (PTS) than students using the (VR) mode.

Descriptive of the posttest scores of students in groups: Comparison was made between groups based upon the mean of the posttest scores (Table 2). It showed a difference between the means of post test scores for group using AR mode and group using VR mode. The mean of post test score for group using AR mode (15.50) was higher than the mean of post test score for group using VR mode (13.72). 
Table 2. Descriptive of the Posttest Score of Students in Groups

\begin{tabular}{|l|c|c|c|}
\hline \multicolumn{1}{|c|}{ Groups } & Mean & Std. Deviation & N \\
\hline AR & 15.5000 & 2.47179 & 42 \\
\hline VR & 13.7273 & 2.42433 & 44 \\
\hline Total & 14.5930 & 2.59129 & 86 \\
\hline
\end{tabular}

ANCOVA of Post Score of Students in Various Treatment Groups

Table 3 shows the degree of relationship between pretest score and posttest score. A correlation coefficient $R=0.603 * *$ indicates a high positive relationship between two variables.

Table 3. Correlation between Pretest Scores and Posttest Scores

\begin{tabular}{|l|l|c|c|}
\hline & & Pretest & Posttest \\
\hline \multirow{3}{*}{ Pretest } & Pearson Correlation & 1 & $.603(* *)$ \\
\cline { 2 - 4 } & Sig. (2-tailed) & & .000 \\
\cline { 2 - 4 } & $\mathrm{N}$ & 86 & 86 \\
\hline \multirow{3}{*}{ Posttest } & Pearson Correlation & $.603(* *)$ & 1 \\
\cline { 2 - 4 } & Sig. (2-tailed) & .000 & \\
\cline { 2 - 4 } & $\mathrm{N}$ & 86 & 86 \\
\hline
\end{tabular}

**. Correlation is significant at the 0.01 level (2-tailed).

Based on a correlation coefficient $R=0.603 * *$ (Table 3 ) indicated a high positive relationship between the pretest scores and the posttest score. In order to reduce the statistical error, the pretest scores was used as the covariate variable and a comparison was made among the groups (AR \&VR) using the ANCOVA procedure (Table 4)

Table 4. ANCOVA of the Posttest Score of Students in Groups

\begin{tabular}{|l|c|c|c|c|c|}
\hline \multicolumn{1}{|c|}{ Source } & $\begin{array}{c}\text { Type III Sum of } \\
\text { Squares }\end{array}$ & Df & Mean Square & F & Sig. \\
\hline Corrected Model & 279.966 & 2 & 139.983 & 39.955 & .000 \\
\hline Intercept & 625.598 & 1 & 625.598 & 178.564 & .000 \\
\hline pre-test & 212.437 & 1 & 212.437 & 60.636 & .000 \\
\hline Groups & 72.665 & 1 & 72.665 & 20.741 & .000 \\
\hline Error & 290.790 & 83 & 3.503 & & \\
\hline Total & 18885.000 & 86 & & & \\
\hline Corrected Total & 570.756 & & & \\
\hline a. R Squared =.819 (Adjusted R Squared =.818) \\
\hline
\end{tabular}

Table 4 indicated the results of ANCOVA test of statistical significance on the differences observed in the mean score of the posttest for the groups with $F(1,83)=$ 20.741, Mean Square $=72.665$ and $p=0.000$. Therefore, these differences in the post test scores among the groups were significant.

Summary of testing hypothesis: The statistical results support the hypothesis, that is, the students using the AR mode performed significantly better than students using the VR group.

H2: Students using the Augmented Reality mode will attain significantly higher visual thinking test score than students using the Simulation mode. 
Visual thinking test score of students in the groups: The corresponding hypothesis is stated as below

Students using the (AR) mode will attain significantly higher visual thinking test score (VTTS) than students using the (VR) mode

Descriptive of the visual thinking test score of students in groups: Comparison was made between groups based upon the mean of the visual thinking test scores (Table 5). It showed a difference between the means of visual thinking test for group using AR mode and group using VR mode. The mean of visual thinking test score for group using AR mode (15.7381) was higher than the mean of visual thinking test score for group using VR mode (14.1136).

Table 5. Descriptive of the Visual Thinking Test Score of Students in Various Treatment Groups

\begin{tabular}{|l|c|c|c|}
\hline \multicolumn{1}{|c|}{ Groups } & Mean & Std. Deviation & N \\
\hline AR & 15.7381 & 2.70555 & 42 \\
\hline VR & 14.1136 & 3.02098 & 44 \\
\hline Total & 14.9070 & 2.96897 & 86 \\
\hline
\end{tabular}

T-test of visual thinking test of students in groups: Table 6 indicated the results of T-test of statistical significance on the differences observed in the mean score of the visual thinking test for the groups. Therefore, these differences in the visual thinking test scores among the groups were significant.

Table 6. T-test of the Visual Thinking Test Score of Students in Groups

\begin{tabular}{|l|l|l|l|l|l|}
\hline & \multicolumn{1}{|c|}{ Groups } & N & t & df & Sig. \\
\hline $\begin{array}{l}\text { Visual Thinking } \\
\text { Test Score }\end{array}$ & Augmented & 42 & 2.623 & 84 & .010 \\
\cline { 2 - 6 } & Virtual & 44 & 2.623 \\
\hline
\end{tabular}

Summary of testing hypothesis: The statistical results support the hypothesis, that is, the students using the AR mode performed significantly better than students using the VR group.

\section{Discussion of the Result}

The researchers attribute this result to the fact that the augmented reality is alive, so that modifications are added to display of the real world are at the same time, not at separate times, and merged together in one template. This increases the strength and interconnectedness of the display, which is reflected in the visual thinking and achievement of learners. This result can be attributed to the fact that the augmented reality has the potential to integrate the real world with the virtual world, so the information and facts can be presented to the learner and added through augmented reality, while these facts and information have an important impact and a significant role in developing, increasing and enhancing the learner's visual thinking and achievement. In addition, the real world has become more interactive with learners 
through technical development, which increases the learner's ability to roam within the augmented reality, that is often in fact, and to closely observe for all details in the geometric shapes that the learner can observe in the real world through buildings and others merged with some additions which had a great effect on enhancing visual thinking and increasing collection. The student builds new information gained from old information, facts and concepts that are obtained from the real world because this information is stored with the learner, so it is easy to motivate it through the augmented reality that connects the learner to it. This information may be like geometric shapes known by the learner in his real world but does not represent him anything; but with its linkage and integration into the augmented reality template it becomes understandable that it was easy for the learner to learn. The possibility of wandering has a great impact on the learner's increase in investigation, exploration, inference and selflearning. The learner finds himself in his environment, which he is not isolated from, and has the desire to explore

Augmented reality also has a great impact on learners through the suspense, excitement and novelty factors, that increase the learner's desire to learn and integrate into this augmented reality, which develops visual thinking and achievement. In addition to three-dimensional graphics that further illustrate the concepts and realities with the program's mobility, the learners deepen their visual thinking and increase collection. However, the augmented reality is based on the constructivism of learning by integrating theoretical and applied learning in one form and at the same time. Moreover, the augmented reality increases the learner's correlation with the reality around him and its detailing and fragmentation which makes it easier for the learner to analyze and construct it, as well as to distance the learner from the non-logical fiction, since the augmented reality does not separate the learner from the real world he lives in.

The augmented reality also shortens the learner's time and effort in promoting and developing his or her visual thinking and increasing his/her learning, by using more than one sense in an environment that integrates the learner. Augmented reality has the ability to bring the distance and things that are difficult to be visualized in a real life for some age levels of students, when it adds the touches that given by the movement and the triple dimensions that reinforce what the learner sees as fiction and unrealistic in nature and truth as the shape of the room, the building and the pyramid. In addition to the fact that the augmented reality has a great importance in mathematics in general and specially in engineering, since it provides learners with the ability to know the dimensions, angles, shapes and distinctive characteristics between the shapes through visual thinking and informational visualization. Furthermore, the augmented reality works to employ the old information in new positions, and the current information in future educational positions; It provides a structured learning, in addition to providing instant feedback, which is reflected in visual thinking and collection.

The use of simulation technology by users is too little from expert view, and it needs a long time to spread significantly even though its prices have fallen, but remains expensive. The virtual world also has not been able to put us in an environment that brings us closer to reality and enables us to wander around the place in contrast to 
the augmented reality that reflects a factual reality that benefits individuals, learners and in many areas, because it introduces digital information to the real world. The simulation makes the learner present in the virtual reality in a mental form and is far from the reality in his body, and is separated and isolated from reality, but the augmented reality promotes the learner's association with the factual reality with an increase in clarity about it, so the learner feels that $\mathrm{s} / \mathrm{he}$ is in a real world. The result can also be attributed to the possibility of interaction between the learner and the teacher, and the learner's possibility to add some additions.

\section{Conclusion and Recommendations}

This study presented the effects of augmented reality and simulation on the achievement of mathematics and visual thinking among students. The results show that while augmented reality use increases student's achievement, and visual thinking. This study gives support to the effect of augmented reality of mathematics achievement and visual thinking among students. As a result, it can be stated that the applications developed with augmented reality technology can be used as effective tools in mathematics better than simulation. The augmented reality use to increased student achievement and visual thinking. Based, that the new studies can be planned in different fields and by using different sample levels. and focus on the training of teachers and students in this type of teaching methods. And its effect among several thinking skills. And its effect among achievement and visual thinking skills. As that review, helps to develop teaching strategies. The researcher suggests other variables, such as cognitive pattern, learning pattern, student ability, intelligence level and ability.

In short, the study strongly indicated that augmented reality was effective in promoting better learning of mathematics and visual thinking skills. It is suggested that augmented reality should be integrated into all courseware on the learning of mathematics.

\section{References}

[1] Abdul Aziz, Hamdi Ahmed. (2013). Designing an electronic learning environment based on computer simulation and its impact on the development of some office business skills and improving the learning depth skills of high school commercial students. Jordanian Journal of Educational Sciences, 9 (3) 275-292.

[2] Abdul Karim, Saad (2010). The impact of some modern teaching methods on the professional satisfaction and performance of science teachers. Journal of Scientific Education. 13 (5) 139-166, Egypt.

[3] Abu Dan, Maryam (2013). The Effect of the Use of Meaningful Models in Teaching the Fracture Unit on the Development of Achievement and Visual Thinking Skills of Fourth Grade Students in Gaza, Unpublished Master Thesis. Faculty of Education. Islamic University of Gaza.

[4] Abu Madi, Sajida (2011). The Effect of Using Computer Simulation to Acquire Electrical Concepts and Skills by Tastek in Grade 9 Students in Gaza (Unpublished Master Thesis), Islamic University, Gaza. 
[5] Abu Odeh, A. (2018). The level of conceptual and procedural knowledge required for the teaching of mathematics at the basic stage among the students of the Islamic University in Gaza. Unpublished Master Thesis, Islamic University.

[6] Ahmad, E. (2016). The effectiveness of A programme Based on Augmented Reality on Developing Visual Thinking Skills in Science For Ninth Grade Male Students in Gaza. unpublished Master Thesis, Alazhar University.

[7] Ahmed, Khalid and Alastel, Ibrahim. (2015). The effectiveness of a computerized interactive program in the treatment of difficulties in learning mathematics among the fourthgrade pupils in UNRWA schools in the Gaza Strip. Journal of Palestine University for Research and Studies, 8 (2), DOI: 10.12816/0012374.

[8] Alammarji, Jamal Eddin Ibrahim Mahmoud. (2017). Effectiveness of the use of enhanced reality technology in the teaching of history for the first grade secondary on the development of achievement and the skills of historical thinking and motivation to learn using the techniques of students. International Specialized Educational Journal, 6 (4), 135-136.

[9] Aldalalah, O. (2018). The Level of Cyber-bullying (bully, victim) through Smartphone Applications among Students of the Faculties of Education in Jordanian Universities and its Relation to Loneliness. International Journal of Social Sciences \& Educational Studies, 5(1), 145 - 163. https://doi.org/10.23918/ijsses.v5ilp145

[10] Al-Hamdani, R. (2002). Computer Simulation, First Edition, Dar Almnhaj. Jordan.

[11] Al-Hiyawi, Muhib Eddin Mahmoud; Saleh, Omar Basil (2011). The Effect of Modeling (Astronomy) on the Achievement of Students in the Second Grade Department of Physics and the Development of their Attitudes Towards it, Journal of Education and Science, 18, (4), 310-332.

[12] Al-Khalifa, H \& Al-Otaibi, H. (2015). Trends in innovative techniques in e-learning: from traditional to creative. A paper presented at the 4th e-learning conference, Riyadh.

[13] Almousa, N \& Abed, A. (2016). The Effect of Computerized Simulation on Achievement and Interconnection in Islamic Education among Students of Different Kinds of Motivation in the Higher Basic Stage in Jordan. Drasat, Educational Sciences, 43(4), 1669-1691

[14] AL-Musawi, S, Nasaeif, R \& Al-Khafaji, E. (2016). Construction of a training program to teach thinking skills for the students - teachers and its impact on pivotal thinking Of their Pupils. Journal of the Faculty of Education for Educational and Human Sciences, 30, 620640.

[15] Al-Mutairi, Dalal Bent Diab (2016). Will the enhanced reality technology be the future of education in the Kingdom (247), Knowledge Magazine, Ministry of Education, Riyadh.

[16] Al-Sarayra, T., Al-Rifa, A \& Jouifel, M. (2017). perceptions of teachers of physics in Ma'an Governorate of using simulation programs. Journal of Al - Hussein Bin Talal University, 3(2), $160-187$.

[17] Alshalawi, A. (2017). The availability the visual thinking skills are available in the science course of the 6th primary grade. International Specialized Educational Journal, 6(3), 243251.

[18] AlShami, Enas and Alkade, Lamia. (2017). Impact of a training program on the use of enhanced reality techniques in designing and producing electronic lessons At the student Teacher, Faculty of Home Economics, Al-Azhar University. Journal of the Faculty of Education - Menoufia University, 4 (1), 124-153

[19] Alsultanny, Y., Nouby, A. and Enazi, T. (2014). Effect of Simulation in e-learning Programs on misconceptions and Motivations towards Learning, Academic Journal. 5(2): 4051.

[20] Amasha, Mohamed (2011). The impact of a training program on intelligent Web 2.0 technologies for e-learning to be used in the design and dissemination of e-lessons to faculty 
members in light of their training needs. Education Technology: Studies and Research. Arab Association for Educational Technology (12) October Page 275 - 277. Egypt

[21] Anderson, E,. \&Liarokapis, F. (2014). Using Augmented Reality as a Medium to Assist teaching in Higher education. Coventry University.UK.

[22] Aqel, M \& Azzam, S. (2018). Effectiveness of Employing the Augmented Reality Technology in the Development of the Achievement of Seventh Grade Students in Chemistry in the Gaza Strip. International Journal of Learning Management Systems, 6(1), 27-42. https://doi.org/10.18576/ijlms/060103

[23] Azuma. R (1997). A survey of Augmented Reality. Presence: Teleoperators and Virtual, Environments, Vol 1, No 6, P365. https://doi.org/10.1162/pres.1997.6.4.355

[24] Catenazz, N \&Sommaruga, L (2013). Social media: challenges and opportunities for education in modern society, mobile learning opportunities, international interdisciplinary scientific, Vol.1 No.1 .

[25] Chiang, T.-H.-C., Yang, S.-J.-H., \& Hwang, G.-J. (2014). An Augmented Reality-based Mobile Learning System to Improve Students' Learning Achievements and Motivations in Natural Science Inquiry Activities. Educational Technology \& Society, 17 (4), 352-365.

[26] Cho, Y. \& Tee, F. (2018). Complementing Mathematics Teachers' Horizon Content Knowledge with an Elementary-On-Advanced Aspect. Pedagogical Research, 3(1), pp. 111. https://doi.org/10.20897/pr/85172

[27] Ersoy, E., \& Guner, P. (2015). Place of problem-solving and mathematical thinking in the mathematical teaching. The Online Journal of New Horizons in Education, 5(1), 120-130.

[28] Eubayd, M. (2014). Use of computer simulations. In the teaching of architectural drawing. To develop the skills of drawing, visual thinking and attitudes of industrial secondary students. Arabic Studies in Education and Psychology, 48(3) 1- 42.

[29] Farrajallah, A. (2016). The Impact of the Employment of Geogebra Software in Acquiring Some Visual Thinking Skills and On the Academic Achievement among 8th Grade Students. IOSR Journal of Mathematics, 12 ( 2), 53-64.

[30] Husseini, Maha Bent Abdul Moneim Mohammed (2014). Effect of the use of enhanced reality technology in the unit of the computer curriculum in the collection and direction of secondary school students (unpublished master thesis). Umm Al Qura University, Saudi Arabia. https://doi.org/10.17140/drmtoj-1-106

[31] Ibrahim, Majdi Aziz (2012). Innovation is the cornerstone of modernizing the educational curriculum. World Books, Cairo.

[32] Karimi, A \& Venkatesan, S. (2009). Mathematics Anxiety, Mathematics Performance and Academic Hardiness in High School Students. International Journal of Education Science, 1(1): 33-37. https://doi.org/10.1080/09751122.2009.11889973

[33] Khamis, Mohamed (2015). Virtual reality technology, enhanced reality technology and blended reality technology. Journal of Educational Technology, 25 (2), 1-3 April, Egypt.

[34] Koparan, T \& Yilmaz, G. (2015). The Effect of Simulation-based Learning on Prospective Teachers' Inference Skills in Teaching Probability. Universal Journal of Educational Research 3(11): 775-78. https://doi.org/10.13189/ujer.2015.031101.

[35] Kulkarni, S \& Takawale, N. (2016). Comparative Study of Augmented Reality and Virtual Reality. International Journal of Innovative Research in Computer and Communication Engineering, 4(11), 1947 - 1952. DOI: 10.15680/IJIRCCE.2016. 041105120034

[36] Larsen.Y..Bonger.F.Buchholz.H. and Brosda.C.(27- 29)October,(2011).Evaluation of A portable and interactive Augmented Reality Learning system By Teachers And students, open classroom conference augmented reality in education, Ellinogermaniki Agogi. Athens, Greece. p41. 
[37] Liu,C., Cheng, Y "https://www.sciencedirect.com/science/article/pii/S0360131511000832" \& "https://www.sciencedirect.com/science/article/pii/S0360131511000832" Huang, C. (2011). The effect of simulation games on the learning of computational problem solving. Computers 57(3), 1907-1918. https://doi.org/10.1016/j.compedu.2011.04.002

[38] Maqat, k. (2016). Effect of Using Computerized Simulation on Developing the Skills of Designing Logical Circuits in Technology among Ninth Graders in Gaza. unpublished Master Thesis, Islamic University.

[39] Masoudi, Abeer Bint Mohammed; Al Mazrou', Haya Bint Mohammed (2014). The effectiveness of computer simulations according to the survey in the development of conceptual understanding in physics among secondary school students. Studies, Educational Sciences, 41 (1), $173-191$.

[40] Mazen, Hossam Mohamed (2009). Modern Modern Trends in Curriculum Development and Scientific Education Technology, Arab Renaissance Library: Cairo.

[41] Mokly, F. (2013). The Level of Visual Spatial Perception Among Intermediate School Students. Unpublished Master Thesis, Umm Al Qura University.

[42] Mushtahaa, Rami (2015). Effectiveness of employing the integrated truth technique in the development of creative thinking skills and the trend toward science among the ninth grade student in Gaza (unpublished master thesis). Islamic University.

[43] Nayyar, A., Mahapatra, B., Le, D \& Suseendran, G. (2018). Virtual Reality (VR) \& Augmented Reality (AR) technologies for tourism and hospitality industry. International Journal of Engineering \& Technology, 7 (2.21), 156-160. https://doi.org/10.14419/ijet.v7i2.21. $\underline{11858}$

[44] Nofal, Khalid (2010). Virtual Reality Technology and its Educational Uses, Dar AlManakh for Publishing and Distribution, Amman.

[45] Osaimi, A. (2015). The Effectiveness of the Use of Visual Thinking Networks in the Development of Mathematical Communication Skills at the Sixth Grade Pupils in Makkah.

[46] perez - lopez, D ,\& Contero, M (2013).Delivering educational multimedia contents through an augmented reality application: a case study on its impact on knowledge acquisition and retention, the Turkish journal of educational technology, vol.1, no.24.

[47] Ruwaili, Thamer Taleb. (2011). The Effect of Computerized Simulation in the Achievement of Students of Primary Education in Mathematics in Saudi Arabia. Unpublished Master Thesis. University of Jordan.

[48] Salem, Z \& Abud, A. (2017). Identify the extent to which students of the intermediate stage acquire visual thinking skills. Ork Journal, 10(3), 542-561. DOI: 10.18018/URUK/017-10/542-561.

[49] Salih, E. (2017). Effectiveness of the Strategy of Guided Imagination on the Development of Visual Thinking Skills among the Eighth Grade Students in Yemeni Schools. Journal of Social Studies, 28(2), 53-80.

[50] Samo, D \& Kartasasmita, B. (2017). Developing Contextual Mathematical Thinking Learning Model to Enhance Higher-Order Thinking Ability for Middle School Students. International Education Studies, 10(12), 17-29. https://doi.org/10.5539/ies.v10n12p17

[51] Shaltout, Mohamed Shawki; Fayez, Sarah Abdulaziz (2017). The impact of the use of interactive simulation in the development of achievement among sixth graders in science. International Journal of Internet Education.

[52] Shatat, F. Aldalalah, O., \&. Ababneh, Z. (2017).The Impact of the E-book on Levels of Bloom's Pyramid at ECT Students in Light of the Internal and External Motivation to Learn Mathematics and Statistics. Asian Social Science, 13(2), 49 - 53. https://doi.org/10.5539/ass.v13n2p49 
[53] Sidiq, M., Lanker, T \& Makhdoomi, K. (2017). Augmented Reality VS Virtual Reality. International Journal of Computer Science and Mobile Computing, 6(6), 324 - 327.

[54] Sirakaya, M \& Kiliç, E. (2018). Investigating Student Attitudes toward Augmented Reality. Malaysian Online Journal of Educational Technology, 6(1), 30 - 44.

[55] Sophie, Rabab, (2010). Effectiveness of a Preventive Simulation Program in the Development of Achievement of Genetic Engineering Students, Unpublished Master Thesis. Institute of Educational Studies and Research. Cairo University.

[56] Sumadio, d. \& Rambli, D., (19-21 MARCH 2010). Preliminary evaluation on user acceptance of the augmented reality use for Education, Second international conference on comuter engineering and applications, Bali Island. https://doi.org/10.1109/iccea.2010.239

[57] Surya, E., Sabandar, J., Kusumah, S. \& Darhim, D. (2013). Improving of Junior High School Visual thinking Representation Ability in Mathematical Problem Solving by CTL. Indo-Ms Journal On Mathematics Edfucation. 4(1), 113-126. https://doi.org/10.22342/ ime.4.1.568.113-126

[58] Tafesh, E. (2011). The Effect of a Suggested Program in Mathematical Communication Skills on the Student Achievement and Visual Thinking Skills in Geometry for Female Students of 8th Grade in Gaza. unpublished Master Thesis, Al Azhar university.

[59] Tarigan, F \& Yusnadi, E. (2017). The Difference in Improving Students' Mathematics Understanding and Ability of Visual Thinking by Using Cooperative Learning Model types Think Pair Shared (TPS) and Number Head Together (NHT) At SDN Percobaan Medan. IOSR Journal of Research \& Method in Education (IOSR-JRME), 7(6), 74-81. DOI: 10.9790/7388-0706057481 www.iosrjournals.org 74 | Page https://doi.org/10.24114/ jpkim.v10i2.10774

\section{Authors}

Dr. Osamah (Mohammad Ameen) Aldalalah. Associate Professor in Educational Technology. Taibah University, Madina, KSA and a researcher in education technology and multimedia. E-mail: usm.osamah@gmail.com

Zyad Waleed Mohamed Ababneh bachelor's degree in education (2001).Master of Educational Technologies (2004). ) Teacher at the Ministry of Education (2001), Researcher in educational technology. He is currently working in the Ministry of Education / UAE.

Dr. Ali Khaled Bawaneh Assistant professor of science education in Deanship of Academic Development at Imam Abdulrahman Bin Faisal University in Saudi Arabia. I worked as a lecturer in high diploma in ICT, and Trainer in educational development in Jordan. Has Bachelor in physics, High diploma in teaching science, Master and $\mathrm{Ph}$. $\mathrm{D}$ in science/physics education.

Wafa Mohammad Mahmoud Alzubi bachelor's degree in mathematics (2002) and a high diploma in education curriculum, a teacher in the Ministry of Education since (2005) she has research interests in the fields of education.

Article submitted 2019-04-27. Resubmitted 2019-06-13. Final acceptance 2019-06-19. Final version published as submitted by the authors. 